\title{
CHEMOSPHERE
}

\section{Some aspects of toxic contaminants in herbal medicines}

\author{
K. Chan \\ Research and Development Division, School of Chinese Medicine, Hong Kong Baptist University, Hong Kong, SAR, PR China
}

\begin{abstract}
A World Health Organisation survey indicated that about $70-80 \%$ of the world populations rely on non-conventional medicine mainly of herbal sources in their primary healthcare. In recent years, we have witnessed the increasing growth in popularity of over-the-counter (OTC) health foods, nutraceuticals, and medicinal products from plants or other natural sources in developed countries. This indirectly indicates that the public is not satisfied with their orthodox medical (OM) treatment. Such increase in popularity has also brought concerns and fears over the professionalism of practitioners, and quality, efficacy and safety of their treatment methods and products from herbal and natural sources available in the market. Over the past decade several news-catching episodes in developed communities indicated adverse effects, sometimes life threatening, allegedly arisen consequential to taking of OTC herbal products or traditional medicines from various ethnic groups. These OTC products may be contaminated with excessive or banned pesticides, microbial contaminants, heavy metals, chemical toxins, and for adulterated with orthodox drugs. Excessive or banned pesticides, heavy metals and microbial contaminants may be related to the source of these herbal materials, if they are grown under contaminated environment or during collection of these plant materials. Chemical toxins may come from unfavourable or wrong storage conditions or chemical treatment due to storage. The presence of orthodox drugs can be related to unprofessional practice of manufacturers. Some of these environment related factors can be controlled by implementing standard operating procedures (SOP) leading to Good Agricultural Practice (GAP), Good Laboratory Practice (GLP), Good Supply Practice (GSP) and Good Manufacturing Practice (GMP) for producing these medicinal products from herbal or natural sources. The public's belief that herbal and natural products are safer than synthetic medicines can only be ascertained by imposing regulatory standards on these products that should be manufactured using these Good Practices.

Using Chinese medicines, as examples, this paper illustrate how advances in chemical and biomedical analysis would help to detect intentional and unintentional toxic contaminants in herbal substances. The paper also summarises how modernization and progress are being carried out to get the best out of Chinese medicines for public healthcare.

(c) 2003 Elsevier Ltd. All rights reserved.
\end{abstract}

Keywords: Chemical and biomedical analyses; Heavy metals; Herbal medicines; Pesticides; Proper use of Chinese herbal medicines; Toxic contaminants

\section{Contents}

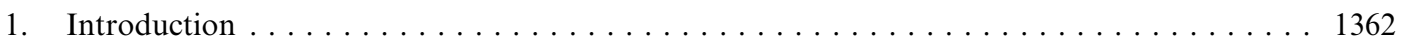

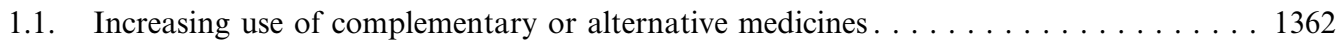

1.2. The emerging market of herbal products . . . . . . . . . . . . . . . . . 1363

1.3. The growing popularity of Chinese medicinal herbs and herbal products in the west. . 1363

1.4. The concern over quality, safety and efficacy of herbal medicine . . . . . . . . . . 1364

E-mail address: profchan@hkbu.edu.hk (K. Chan). 


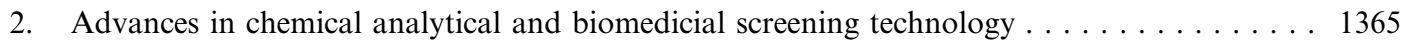

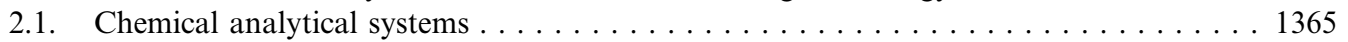

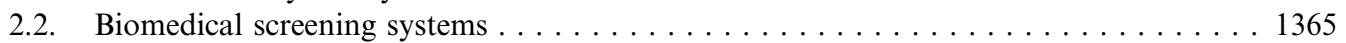

3. Sources of toxic chemicals and contaminations in herbal products . . . . . . . . . 1366

3.1. The use of potent and toxic medicinal materials in Chinese medicinal prescriptions. . 1366

3.2. General considerations on how CHM products produce toxic effects when not used

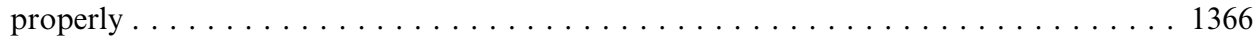

3.2.1. Authenticity or poor quality of CM herbs . . . . . . . . . . . . 1366

3.2.2. The consequence of processing of CM crude herbs . . . . . . . . . . 1367

3.2.3. The quantity of $\mathrm{CM}$ herbs prescribed. . . . . . . . . . . . . . 1367

3.2.4. The likelihood for interaction of drug-CM products interactions . . . . . . . 1367

3.3. The conditions of the patients' welling being and disease state. . . . . . . . . . . . 1367

4. Literature reports on the presence of heavy metals, pesticides, and orthodox drugs in herbal products . . . . . . . . . . . . . . . . . . . . . . . . . . 1367

5. Conclusion: the way forward for assurance of quality, safety and efficacy of herbal medicines 1368

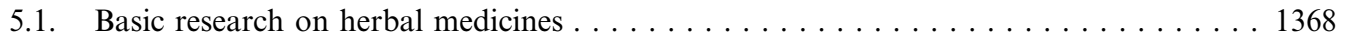

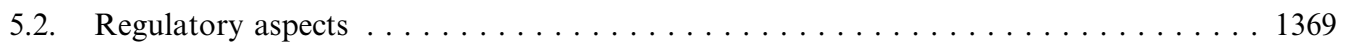

References . . . . . . . . . . . . . . . . . . . . . . . . . . . . . . . . . 1369

\section{Introduction}

About $70-80 \%$ of the world populations, particularly in the developing countries, rely on non-conventional medicine in their primary healthcare as reported by the World Health Organisation (Akerele, 1993). The rest of the populations, in the better-developed countries, have been fortunate receivers of orthodox medicine (OM) or conventional medicine since the early 19 th century. Yet in the present era of rapid advances in biomedical science and technology it is astonishing that the public in rich developed countries spends an significant amount of their earnings on over-the-counter (OTC) herbal products and related non-conventional therapies. Over the past decade we have witnessed two apparently unrelated trends in the biomedical and biotechnological development of medicinal products. There is the rapid development of recombinant DNA technology and related procedures to provide biomedical proteins and related biological products for use as therapeutic drugs, prophylactic vaccines and diagnostic agents (Chan, 1996). The growth in popularity of OTC health foods (nutraceuticals) and medicinal products from plants or other natural sources have taken a very large share of the healthcare market (Johnson, 1997). These two unrelated trends indicate changes in people's perceptions of OM treatment using synthetic drugs or conventional therapies.

\subsection{Increasing use of complementary or alternative medicines}

In most developed countries where $\mathrm{OM}$ assumes full responsibility in national healthcare, where as most forms of traditionally practised medicine and therapies are considered as complementary or alternative medicine (CAM). Some experts consider that OM is allopathic treatment while many of the CAM involve holistic approach; the practitioners of OM attempt to intervene in order to block certain body processes while practitioners of the CAM focus on supporting and working with the body's innate powers of self-regeneration. The WHO has defined CAM as all forms of healthcare provision which 'usually lie outside the official health sector' (Eisenberg et al., 1993). This definition by WHO embraces formalised traditional systems of medicine (Ayurvedic, Chinese, Hindoo and Unani systems etc.), traditional healers and medicine men, feedback, chiropractic, naturopathy, osteopathy, and homeopathy etc. Very little is known concerning the reasons for the increase in popularity of CAM in developed countries. Untested assumptions include the side-effects of synthetic drugs, general dissatisfaction of orthodox treatment, diseases that cannot be cured by $\mathrm{OM}$, and patients with chronic illnesses demanding more attention from OM practitioners. Research is urgently needed in these areas to improve healthcare planning (Chan, 1996). CAM treatments are recommended for chronic pain affecting spine, joints or muscles, for the control of nausea, eczema, and other skin complaints, asthma, cancer and migraine etc. (Lewith et al., 1996). There are over 100 different therapies available as CAM treatments, but the five discrete clinical disciplines (acupuncture, chiropractic, herbal medicine, homeopathy and osteopathy) are distinguished by having established foundations of training and professional standards (British Medical Association, 1993). However it has been pointed out that 
Table 1

Suspected adverse effects of complementary/alternative medicine (modified from Abbot et al. (1996) and Barnes (1997))

\begin{tabular}{|c|c|c|c|c|c|}
\hline \multicolumn{3}{|l|}{ Users' survey } & \multicolumn{3}{|c|}{ General practitioners' survey } \\
\hline Therapy & $\%$ Reporting AE's & $\begin{array}{l}\text { Most commonly } \\
\text { reported AE's }\end{array}$ & $\begin{array}{l}\% \text { Reporting } \\
\text { AE's }\end{array}$ & $\begin{array}{l}\text { Most commonly } \\
\text { reported minor AE's }\end{array}$ & $\begin{array}{l}\text { Most commonly } \\
\text { reported major AE's }\end{array}$ \\
\hline Manipulation & $15.8(24)$ & $\begin{array}{l}\text { Pain (13) } \\
\text { Fatigue (2) } \\
\text { Dizziness (3) }\end{array}$ & $15.4(71)$ & Aggravation (65) & $\begin{array}{l}\text { Fractures (3) } \\
\text { Nerve Damage (2) } \\
\text { Disk Protrusion (1) }\end{array}$ \\
\hline Acupuncture & $12.5(23)$ & $\begin{array}{l}\text { Aggravation (6) } \\
\text { Mental Effects (3) } \\
\text { Fatigue (3) } \\
\text { Pain (2) } \\
\text { Needle trauma (2) }\end{array}$ & $<0.1$ (4) & $\begin{array}{l}\text { Aggravation (2) } \\
\text { Visual Disturbance (1) }\end{array}$ & Septic Arthritis (1) \\
\hline Homeopathy & $9.8(28)$ & $\begin{array}{l}\text { Aggravation (6) } \\
\text { Mental Effects (3) } \\
\text { Digestive Effects (2) }\end{array}$ & $<0.1(9)$ & $\begin{array}{l}\text { Aggravation (5) } \\
\text { Eye Infection (1) } \\
\text { Skin Rash (1) }\end{array}$ & $\begin{array}{l}\text { Liver Failure (1) } \\
\text { Anaphylaxis (1) }\end{array}$ \\
\hline $\begin{array}{l}\text { Herbal } \\
\text { medicine }\end{array}$ & $7.6(10)$ & Digestive Effects (3) & $<0.1(6)$ & $\begin{array}{l}\text { Aggravation (2) } \\
\text { Rashes (2) } \\
\text { Nausea (1) }\end{array}$ & Liver Toxicity (1) \\
\hline
\end{tabular}

Where $\mathrm{AE}=$ adverse effects; numbers in brackets ( ) refer to actual reported incidents.

not all natural therapies or products related to CAM are free from adverse effects (Table 1) (Abbot et al., 1996; Barnes, 1997).

\subsection{The emerging market of herbal products}

Herbal or medicinal plant products in various forms have been available for many hundreds of years for treatment of diseases in both Eastern and Western cultures. About one-quarter of marketed orthodox pharmaceutical medicines is either derived from plant sources or from derivatives of secondary plant metabolites. The success of obtaining new drugs from natural sources is not very encouraging. Several factors are responsible for such observation (Chaudhury, 1992). At present, of about 2000 varieties of minor illnesses and serious diseases only $40 \%$ have cure using conventional orthodox pharmaceuticals (Abbot et al., 1996). Various chemicals and biotechnological products are being screened by major multinational pharmaceutical industries in the hope of discovering new cures for diseases.

Table 2 shows the different types of herbal medicines being practised. It is interested to note that China has a US\$1.3 billion turnover of herbs used in Chinese medicine. In Europe there is significant amount, in the vicinity of about $£ 300$ million, of herbal remedies that the public consumes. In the 1997 meeting of Federation of International Pharmcaceutique (FIP), an officer from United State Pharmacopoeia (USP) indicated a steady increase of $10 \%$ in public spending on remedies of botanical origins. In the same meeting another official from the Food and Drug Administration (FDA) indicated the concern on adverse effects induced by consumption of remedies of natural sources including botanicals. The emerging importance of herbal products cannot be ignored. Aspects of the efficacy, safety and quality of herbal or natural products are the subjects of on-going debates.

\subsection{The growing popularity of Chinese medicinal herbs and herbal products in the west}

Chinese medicinal (CM) products have received most attention and recently gained popularity and attention in the West. Increasing information on CM has been published in the English literature and the debate of efficacy of CM products has begun (Chan, 1995). Zemaphyte, consisting of 10 different CM herbs in the form of an aqueous decoction for the successful cure of atopic eczema, that has been resistant to orthodox treatment, has created greater interest and attention on the use of $\mathrm{CM}$ herbs and proprietary products (Atherton et al., 1992). Increasing concern and fear have also been expressed to their unsupervised use, efficacy, toxicity and quality of these natural products as well as the legal responsibilities of practitioners. Inclusion of orthodox medications such as antibiotics, non-steroidal drugs and steroids in CM patent products was not considered as a positive attribute of $\mathrm{CM}$ in the West (Karunanithy and Sumita, 1991). The use of fake or wrong herbs has contributed a negative opinion about the safety and efficacy of CM products (Jin et al., 1995). Many popular and expensive CM herbs are in short supply and inferior substitutes or fake crude herbs have been found in the UK market (Yu et al., 1995, 1997). Thus, the increasing popularity of herbal products as medications and food 
Table 2

Medicinal products from natural sources in various ethnic cultures

\begin{tabular}{llll}
\hline Complementary medicine & Natural sources & Origins & Recent turnover trade \\
\hline Ayurvedic & $\mathrm{P}, \mathrm{A}, \mathrm{M}$ & India & No figure \\
Chinese & $\mathrm{P}, \mathrm{A}, \mathrm{M}$ & China & $>1.3$ billion US\$ \\
Indusyunic & $\mathrm{P}, \mathrm{A}, \mathrm{M}$ & Pakistan & No figure \\
Islamic & $\mathrm{P}, \mathrm{A}, \mathrm{M}$ & Middle East & No figure \\
Kampo & $\mathrm{P}, \mathrm{A}, \mathrm{M}$ & Japan & Getting competitive \\
Korean & $\mathrm{P}, \mathrm{A}, \mathrm{M}$ & Korea & No figure \\
Other oriental & $\mathrm{P}, \mathrm{A}, \mathrm{M}$ & Other Asian countries & No figure \\
Aromatherapy & $\mathrm{P}$ & European & $£ 14 \mathrm{~m}$ in 1996 (UK figure) \\
Herbalism & $\mathrm{P}$ & European & $£ 38 \mathrm{~m}$ in 1996 (UK figure) \\
Homoeopathy & $\mathrm{P}$ & European & $£ 20 \mathrm{~m}$ in 1996 (UK figure) \\
Botanicals & $\mathrm{P}$ & American & $10 \%$ annual increase \\
\hline
\end{tabular}

P: medicinal plants, A: animal sources, M: mineral sources.

supplements has also produced fear about their quality, safety and efficacy (QSE) with uncertainty about their active compounds (Ernst and De Smet, 1996). This is probably because of the increasing use is causing a shortage of the raw materials and unprofessional trading.

\subsection{The concern over quality, safety and efficacy of herbal medicine}

$\mathrm{CM}$ herbs and their manufactured products have been used for thousands of years for prevention and treatment of diseases in China apart from recently introduced synthetic pharmaceuticals in orthodox medical $(\mathrm{OM})$ practice since the late $1800 \mathrm{~s}$. When used or prescribed according to Chinese medical philosophy and practice, through test of time, those medications and crude materials recorded in the Chinese Pharmacopoeia have been approved for safe use (The Pharmacopoeia Commission of PRC, 2000). The previously mentioned unfavourable incidents have possibly been due to unprofessional practice and shortage of supply. Nevertheless, all medicinal products used in humans and animals should have proven QSE. Problems and difficulties arise in the quality assurance of herbal medicinal products because there are so many unidentified chemical entities in the finished products, and the actual bioactive components are seldom known. Recent advances in analytical chemistry and related disciplines have helped elucidating the complex chemical compositions of $\mathrm{CM}$ herbs. Table 3 summarises the differences between orthodox drugs and CM materials (both crude herbs, known as 'Ying Pin', and ready-made or proprietary products).

Chemical analytical techniques can be applied at different stages of good practices in quality assurance of natural or herbal products, including Good Agricultural Practice (GAP), Good Sourcing Practice (GSP), Good Laboratory Practice (GLP), Good Manufacturing Practice (GMP), and Good Clinical Trial Practice
Table 3

A comparison between properties of Chinese medicinal materials and products and orthodox drugs (adopted from Chan (1995))

\begin{tabular}{|c|c|c|}
\hline \multirow[t]{2}{*}{ Properties } & \multicolumn{2}{|l|}{ Remarks } \\
\hline & CMM products & $\begin{array}{l}\text { Orthodox } \\
\text { drugs }\end{array}$ \\
\hline \multicolumn{3}{|c|}{ Physico-chemical properties } \\
\hline Active ingredients & Often unknown & Known \\
\hline $\begin{array}{l}\text { Availability of pure } \\
\text { compound }\end{array}$ & Rare & Yes \\
\hline $\begin{array}{l}\text { Availability of raw } \\
\text { material }\end{array}$ & Limited & Yes \\
\hline $\begin{array}{l}\text { Quality of raw mate- } \\
\text { rial }\end{array}$ & Variable & Good \\
\hline $\begin{array}{l}\text { Stability of prepara- } \\
\text { tion }\end{array}$ & Uncertain & Good \\
\hline \multicolumn{3}{|l|}{ Biomedical properties } \\
\hline Mechanism of action & Often unknown & $\begin{array}{l}\text { Usually } \\
\text { known }\end{array}$ \\
\hline Toxicological tests & $\begin{array}{l}\text { Usually not avail- } \\
\text { able in animals }\end{array}$ & Mandatory \\
\hline Empirical data & Very important & $\begin{array}{l}\text { Often mean- } \\
\text { ingless }\end{array}$ \\
\hline $\begin{array}{l}\text { Specific adverse } \\
\text { effects }\end{array}$ & $\begin{array}{l}\text { Rare through } \\
\text { experience }\end{array}$ & Frequent \\
\hline Tolerance of therapy & Usually good & Limited \\
\hline Therapeutic window & Wide & $\begin{array}{l}\text { Usually nar- } \\
\text { row }\end{array}$ \\
\hline $\begin{array}{l}\text { Suitability for chronic } \\
\text { use }\end{array}$ & Often well tested & $\begin{array}{l}\text { Not yet tested } \\
\text { for new drugs }\end{array}$ \\
\hline Placebo controls & $\begin{array}{l}\text { Difficult to achiev- } \\
\text { able }\end{array}$ & Achievable \\
\hline $\begin{array}{l}\text { Controlled clinical } \\
\text { trial }\end{array}$ & $\begin{array}{l}\text { Usually not avail- } \\
\text { able }\end{array}$ & Mandatory \\
\hline
\end{tabular}

(GCTP). This review paper addresses how using modern analytical methodologies to assess contaminants that may be detected from these materials. Data from these analyses will provide a range limit accepted generally according to guidelines for food substances. We can 
then make calculated estimates for the assurance of QSE of CM or other herbs and their ready-made products. Different government bodies from different countries will have different regulatory controls over products from herbal or natural sources (Chan, 1997).

\section{Advances in chemical analytical and biomedicial screening technology}

\subsection{Chemical analytical systems}

For the past 40 years, chromatography and spectroscopy have been used to study chemical compositions of $\mathrm{CM}$ herbs and plants. Using the methods of gas chromatography (GC), high performance liquid chromatography (HPLC), ultra-violet spectroscopy (UV), infra-red spectroscopy (IR), Raman spectroscopy, nuclear magnetic resonance spectroscopy (NMR), mass spectroscopy (MS), X-ray diffraction, GC-MS and HPLC-MS, many chemical compounds from CM herbs have been isolated and identified. Recently, capillary electrophoresis has been used to infer the botanical sources and to assess the quality of Ephedrae Herba (Liu et al., 1993), Coptidis Rhizoma (Liu et al., 1994), Ginseng Radix (Chuang et al., 1995) and Paeoniae Radix (Chuang et al., 1996). Increased sensitivity has been achieved by coupling HPLC or GC with other analytical systems. For instances, the combination of liquid chromatography and tandem mass spectrometry was efficient to detect co-eluting, closely related substances (Covey et al., 1986) and to quantify active components from traditional Chinese medicine over a concentration range of $1 \mathrm{ng} / \mathrm{ml}$ to $10 \mu \mathrm{g} / \mathrm{ml}$ (Wang et al., 1997).

The successes of eventual launching new drugs using these conventional approaches have been very disappointing (Chan, 1995) even though several effective single chemical entities have been found, some with their definite chemical structure modifications (Table 4). In CM practice, synergistic actions provided by some chemically unknown or not isolated ingredients in composite prescriptions have proven effectiveness from double blind clinical trials. Thus these analytical methods may not be appropriate for quality/efficacy assurance.

\subsection{Biomedical screening systems}

Problems related to chemical analysis have been identified that the level of the active (secondary metabolites) components may be affected by physiological conditions, harvesting period and storage conditions. Moreover, closely related plant species may contain similar chemical components from which a definite botanical identification is not always possible. In some cases, the chemical method usually requires large amounts
Table 4

Some pharmacologically active principles isolated from Chinese medicinal plants (adopted from Chan (1995))

\begin{tabular}{ll}
\hline Chemical type & Number of compounds isolated \\
\hline Alkaloids & 213 \\
Terpenes & 36 \\
Monoterpenes & 39 \\
Sesquiterpenes & 49 \\
Diterpenes & 65 \\
Triterpenes & 25 \\
Cardiac glucosides & \\
Phenolic compounds & 34 \\
Quinonis & 9 \\
Chromones & 49 \\
Flavonoids & 34 \\
Coumarins & 42 \\
Lignans & 25 \\
Phenyl propanoids & 75 \\
Others & 66 \\
Acids, amides and & \\
$\quad$ miscellaneous & \\
Total & 761 \\
\hline
\end{tabular}

of samples for a proper analysis and some of the instruments such as HPLC; capillary electrophoresis and mass spectrometry are expensive and may not be available in many analytical laboratories.

Classical cytogenetic methods including chromosome counting and karyotyping may also be used to differentiate medicinal materials (Honda et al., 1994) and play a role in assessing hybridity of plants (Magdalita et al., 1997). Nevertheless, it is not useful in differentiation of closely related species. Proteins have been exploited as identification markers in Epimedium species (Koga et al., 1991), and to differentiate inter- and intra-species of Panax ginseng (Sun et al., 1993; Koren and Zhuravlev, 1998). One of the drawbacks of such markers is that the protein patterns vary in different tissues, developmental stages and environment as a consequence of temporal and spatial gene expression. Distinguishable markers may also not be easily detected in closely related species and protein is prone to degradation after prolonged storage of the herbs.

DNA molecules are reliable markers for informative polymorphisms as the genetic composition is unique for each individual and is less affected by age, physiological conditions as well as environmental factors. Additional advantages of DNA markers include: Firstly, small amount of sample is sufficient for the analysis, which is particularly relevant for CM materials that are expensive or in limited supply, and secondly, the physical form of the sample for assessment does not restrict detection. The DNA materials can be extracted from leaves, stems or roots of the herbal materials. Therefore DNA fingerprinting can be very useful to assess and confirm the species of the plant materials of interest. 
Other established conventionally in vitro, in vivo and in situ or ex vivo techniques for pharmacological and toxicological screening may be more appropriate for screening purposes for the bioactivities of CM herbs and products as most of the CM formulary products are in combinations of multiple herbs. These techniques can be applied for the studies of other herbal medicinal materials using their crude extracts or bio-active fractionguided approaches.

\section{Sources of toxic chemicals and contaminations in herbal products}

The practices of most ethnic herbal medicine include the use crude or raw herbs that are collected from the wild or from cultivated fields and their prepared or ready-made (formulated mixture of herbal or other natural materials) products. Toxic contaminants may come from:

- Environments and conditions that the medicinal plants are grown or collected.

- The conditions under which they are dried and processed.

- The storage conditions and conditions during transport.

- The manufacturing processes when the ready-made medicinal products are produced.

\subsection{The use of potent and toxic medicinal materials in Chinese medicinal prescriptions}

Some CM natural herbs listed in the official Chinese Pharmacopoeia, CP (The Pharmacopoeia Commission of PRC, 2000) are considered poisonous or toxic due to the presence of poisonous or toxic chemical constituents in the herbs. Of which about 50 of animal, plant and mineral natural materials are included in the CP. In CM they are seldom prescribed or used alone. In the CP the words "toxic, non-toxic, very toxic or slightly toxic" are often used in describing Chinese Materia Medica. Nontoxic herbs, sometimes referred to as 'Superior Class', are moderate or mild in nature and, generally speaking, do not possess any side effects. Toxic herbs, sometimes referred as 'Low Grade' herbs and used for specific purposes in a traditional CM prescription, can cause symptomatic reactions and adverse effects. No overdose of these should be prescribed or given. Examples are processed aconite root (Fuzi) and Nuxvomica seed (Maqianzi) as cited in the present Compendium.

$\mathrm{CM}$ herbs are often prescribed in $\mathrm{Fu}$-Fang (composite formulae) according to CM principles of diagnosis and treatment. This approach of combining of processed poisonous or toxic herbs and non-toxic herbs with the latter neutralises or reduces the toxicity of the poisonous herbs. The different characteristics of herbs in a given prescriptions, consumed orally as aqueous decoction, rectifies the hyper-activity or hypo-activity of $Y$ in and Yang in the unwell body, consequently curing the diseases that have caused the imbalance of Yin and Yang, and restoring health. Different combinations of herbs can cause variation in therapeutic effects. Traditionally the result of combining herbs can be classified as mutual reinforcement; mutual assistance; mutual restraint or mutual counteraction; mutual suppression; and mutual antagonism. Based on the CM principles of Fu-Fang-Xue (Studies of Herbal Combination), the poisonous herbs present in formulae have been included in some wellused prescriptions over a long period of time according to recorded experience. The poisonous herbs that are included in Fu-Fang should be processed according to laid down procedures listed in the Pharmacopoeia or other CM guidebooks.

\subsection{General considerations on how CHM products produce toxic effects when not used properly}

Similar to using orthodox medicines it is understood that all drugs are toxic at high doses. Although the 48 CM materials described in the Pictorial Compendium for potent and poisonous CMMs (Xu and Chan, 1994) are recorded in Pharmacopoeia as poisonous herbs they are used, after special treatments according to traditional processing procedures, in herbal combinations with other non-toxic herbs according to CM diagnosis and treatment. With practice experience and good knowledge of CM herbs the practitioners seldom come across any problems (Chan, 2002). Among many factors, possible reasons for occurrence of adverse effects and toxicity in using $\mathrm{CM}$ are discussed.

\subsubsection{Authenticity or poor quality of $C M$ herbs}

Popularity and scarcity of certain CM herbs may encourage traders to sell poor quality herbs. Misuse and confusion of names of certain CM herbs enhances difficulty in identifying the correct herbs in the market. Some traders supply fake herbs that are poisonous.

Substitution or adulteration with more toxic herbs may occur erroneously, when the herb is incorrectly identified, or deliberately for economic reasons when a cheaper herb is supplied to replace a safer, more expensive one. The most widely publicised reports were the cluster of cases of rapidly progressive interstitial nephritis in Belgium (Vanhaelen et al., 1994). Following investigation, this problem was attributed to the substitution of Aristolochia fangchi instead of the CM herb Stephania tetrandra in a combined slimming regimen that included some orthodox medications. Aristolochic acid from Aristolochia fangchi is a known nephrotoxin, and the other orthodox drugs present such as acetazolamide in the slimming medication could have poten- 
tiated this toxic effect. Most of the cases involved were young women, and some developed irreversible endstage renal failure and/or carcinoma in the urinary tract.

\subsubsection{The consequence of processing of CM crude herbs}

All CM herbs are processed or prepared from fresh after collection with appropriate procedures before use. The processing, apart from cleaning and preserving purposes, removes or reduces the toxic components in the unprocessed crude herbs which when taken alone will cause fatal effects. Certain processing changes the effects of some herbs. For example, raw Radix Rehmanniae is mainly used to purge heat, or cool the blood and promote the generation of body fluids. But Radix Rehmanniae Preparata has a warm property and is especially effective for enriching blood. After processing the therapeutic effects of some herbs will be enhanced. For example, Rhizoma Corydalis processed with vinegar has greater analgesic effect. If the supplied herbs in the market of developed countries have not been processed properly could lead to toxicity, especially so when used without composite prescriptions (Chan, 2002).

\subsubsection{The quantity of $C M$ herbs prescribed}

This refers to the dosage of each herb used in the composite prescriptions-(Fu-Fang) and depends on how well trained and experienced is the practitioner who prescribes. General guidelines are listed in each of the monographs of CM herbs and composite formulae as reference for use. Thus overdosing should be avoided. This is also related to the quality of herbs supplied. Potent or poisonous herbs, if not properly processed and checked, will produce adverse effects even when used as components in composite formulae.

\subsubsection{The likelihood for interaction of drug-CM products interactions}

Reports have reviewed potential interactions between herbal medicines and drugs. These have focused mainly on the herbs used in the west especially for ginseng and ginkgo biloba, which are widely used in Asian countries. Ginseng has been reported to interact with phenelzine and other monoamine inhibitors causing a central nervous system (CNS) stimulant effect (Jones and Runikis, 1987). The anticoagulant effect of warfarin was decreased when ginseng was also taken simultaneously (Janetzky and Morreale, 1997). Digoxin levels were elevated in a patient who took a preparation labeled as Siberian ginseng, Eleutherococcus senticosus, (McRae, 1999), but there were no signs of toxic effects. We reported the clinical observations on interactions between some popular CM herbs and warfarin with experimental animal studies. Danshen (Salvia miltiorrhiza) had effects on both the pharmacodynamics and pharmacokineties of warfarin in rats (Lo et al., 1992), whereas danggui (Angelica sinensis) affected the pharmacodynamics but not the pharmacokinetics of warfarin in rabbits (Lo et al., 1995).

However, there are very few publications in the English language that report interactions between $\mathrm{CM}$ substances and orthodox drugs. We have recently compiled a list of $\mathrm{CM}$ and drug interactions (Chan and Cheung, 2000). We have also observed that not all interactions between $\mathrm{CM}$ products and orthodox drugs are harmful; some were beneficial when both $\mathrm{CM}$ products and OM drugs are combined. All commonly used CHM crude herbs and ready-made CM products have been listed against orthodox drugs for warning of likely and clinically important herb-drug interactions.

\subsection{The conditions of the patients' welling being and disease state}

Many patients are very ill by the time they consult the CM practitioners. Some would consider CM treatment as their last hope for recovery. The incidents of adverse effects could be higher in this group of patients. Because of the aging processes many elderly patients would have compromised body functions; in particular, the cardiovascular system, liver function, and renal function. Moreover many of these patients have been undergone poly-pharmacy scheme of drug treatments. Therefore the likelihood for occurrence of drug-CHM products interactions is relatively high in this subgroup.

\section{Literature reports on the presence of heavy metals, pesticides, and orthodox drugs in herbal products}

Contamination or adulteration of CM products with heavy metals such as lead, mercury, cadmium, arsenic, or thallium is of concern. A number of case reports have been published (Wu, 1992; Wong et al., 1993; Ueng et al., 1997; Liang et al., 1998; Au et al., 2000; Koh and Woo, 2000), and the problem was discussed in the following sections. However some CM products do contain heavy metals as essential ingredients. The poor quality control of these products causes health hazard as some products may present unusually high concentrations of potent and poisonous ingredients that could lead to fatality if consumed. The presence of pesticides, excessive microbial growth and orthodox drugs in some herbal products has been reported:

- A review article (Koh and Woo, 2000) with 58 references reported excessive toxic heavy metals and undeclared drugs in Chinese proprietary medicines (CPM) in Singapore between 1990 and 1997. The names, uses, toxic heavy metals or drugs detected and the year of detection are tabulated. Information on the brand or manufacturer's name are provided whenever available. The public and health care 
professionals should be better informed of the basic concept of traditional CM and its usefulness, as well as the potential adverse effects associated with its use. Greater control over the safety and quality of CPM could be achieved through GMP, regulatory control, research, education, reporting usage of Chinese medicine (as in drug history) as well as reporting of adverse events.

- Lead, arsenic, mercury and any undeclared drugs have been detected in CPM using ICP/MS and atomic absorption spectroscopy. A database for the CPM was established and used to educate the public, the herbal industry and medical professionals (Au et al., 2000).

- In a research report (Liang et al., 1998), the authors measured various metallic elements by atomic absorption spectrophotometer $(\mathrm{K}, \mathrm{Na}, \mathrm{Mg}, \mathrm{Ca}, \mathrm{Fe}$, $\mathrm{Cu}, \mathrm{Zn}, \mathrm{Mn}, \mathrm{Co}, \mathrm{Cr}, \mathrm{Ni}$, Mo and heavy metals As, $\mathrm{Pb}$, and $\mathrm{Cd}$ ) in some Chinese herbal medicines. The results showed: Lonicera japonica Thunberg dry flowers (each $100 \mathrm{~g}$ ) had potassium ion $1.11 \mathrm{~g}$, magnesium ion $9.43 \mathrm{mg}$, copper ion $2.76 \mathrm{mg}$, zinc ion $5.06 \mathrm{mg}$, Radix Glycyrrhiza uralensis Fischer et DC's (each $100 \mathrm{~g}$ ) had magnesium ion $37.2 \mathrm{mg}$, calcium ion $358.8 \mathrm{mg}$, heavy metals detected in Lonicera japonica Thunberg's dry flos and Radix Morinda officinalis How's (each $100 \mathrm{~g}$ ), the arsenic ion was over $10 \mathrm{mg}$.

- A review (Ueng et al., 1997) with 51 references summarized the toxicity of some commonly used traditional CMs in terms of acute, systematic, genetic, analytic, and clinical toxicology. Acute toxicity study showed that herbal medicines and their chemical constituents exhibited LD50 values ranging from the practically non-toxic to super-toxic categories. Target organs of traditional CM-induced toxicity investigated including liver, kidney, gastrointestinal tract, nervous, and cardiovascular systems. Some TCM showed mutagenicity by the Ames test, increased the incidence of unscheduled DNA synthesis, micronucleus formation, and chromosomal aberration in cytogenetic assays. Some TCM products were contaminated with pesticides and heavy metals and adulterated with western drugs. Improper dispensing and use of traditional CMs and individual idiosyncracy may result in adverse effects and fatalities. The paper suggested that future TCM research, new drug development, and safety evaluation should require adequate toxicity testing and mechanistic toxicological studies.

- A research article (Wong et al., 1993) reported the concentrations of nine heavy metals, cadmium, cobalt, copper, iron, manganese, nickel, lead, zinc, and mercury in 42 Chinese herbal medicinal (CHM) plants spectrophotometrically. Generally, the samples contained, relative to the other trace metals, higher concentrations of iron, manganese, and zinc.
The concentration range of the metals was comparable to that reported in many of the East Asian vegetables and fruits. A few samples contained relatively higher concentrations of toxic metals such as cadmium, lead, and mercury. This report suggested that the presence of heavy metals was probably caused by contamination during air-drying and preservation.

- A review (Wu, 1992), with 45 references, reported studies of metabolism and toxicity of trace elements and revealed important interactions between heavy metals $(\mathrm{Cd}, \mathrm{Pb}$, and $\mathrm{Hg})$ and some essential trace elements such as $\mathrm{Zn}, \mathrm{Fe}, \mathrm{Se}, \mathrm{Cu}, \mathrm{Cr}$, and $\mathrm{Mn}$. In general, a deficiency of these essential trace elements increased the toxicity of heavy metals, whereas excess appeared to be protective. These suggest that the presence of the dietary essential trace elements may contribute to the protection of man from the detrimental effect of heavy metal exposure, while their deficiency may increase toxicity. Some traditional Chinese drugs are especially rich in essential trace elements. Appropriate use of these CM materials in dietary manipulation might be valuable in the prevention and treatment of heavy metal poisoning and maintenance of healthy conditions.

\section{Conclusion: the way forward for assurance of quality, safety and efficacy of herbal medicines}

\subsection{Basic research on herbal medicines}

Although herbal medicines have been used in clinical practice for thousands of years, basic research programmes on CM substances should be focused on the toxicity and efficacy relationship for those potent and poisonous herbal substances according to the principles as practiced in Chinese medicine with doses applied for composite formulae.

To overcome those environment factors that are related to contaminations from pesticide residues and heavy metals there should be control measures to implement necessary standard operating procedures (SOP) for GAP and Good Sourcing Practice (GSP) at source. GLP and GMP are also needed to produce good quality medicinal products from herbal or natural sources.

Due to the particular concern of toxicity, poor quality and adulteration of ready-made herbal medicinal products in the market the priority of research on product-related treatment, in particular herbal products, is to ensure QSE of the end products used by consumers. For the majority of cases, the biologically active chemical compounds of these products are unknown even other known chemical entities have been isolated. It has also been shown that single compound isolated from organic solvents is either too toxic or with no therapeutic activities. Most traditional medicinal herbs are 
used in the form of an aqueous decoction. Therefore research projects should be centred on development of analytical and biological procedures for use to give the quality assurance and control, and clinical assessment of efficacy and safety of these products. I have been involved with institutes in China to develop procedures linking analytical with bio-activity patterns or fingerprintings follow by fuzzy logic computing techniques for interpretation on $\mathrm{CM}$ herbs and herbal prescriptions (official Fu-Fang mixtures of several herbs, administered as decoction). After a series of 'training set' inputs of using authenticated aqueous herbal extracts, individual herbs or mixtures of herbs, a 'standard' pattern is used as the reference guide for subsequent assessment. This type of approaches will generate patterns as reference and for prediction and recognition purposes for further research on individual pure active chemical entities (Chan et al., 1995).

\subsection{Regulatory aspects}

All CM or other ethnic herbal products when supplied, as medications, should be regulated for safety, quality and for appropriate evidence of efficacy. It advocates the establishment of a new category of licensed herbal medicines, prepared in accordance with current Good Manufacturing Procedures (cGMP), which meet standards of safety and quality, and which are regulated by local government health department that should have reciprocating arrangements with organizations such as the Medicines Control Agency in the UK, FDA in the USA and those in the European Union.

The licensing requirements in this new category (i.e. herbal medicines) may not be as demanding as those currently apply to licensed medicines. Specifically, the "level of proof" of activity may not need to be as high as for allopathic medicines. Efficacy may be accepted on the basis of documentation of traditional use over a long period, as suggested by WHO.

Safety may deem to have been demonstrated by virtue of traditional use. However, these products ought to be required to substantiate a history of safe use, preferably in the EU for the dosage and indications for treatment to be approved, and the license should clearly indicate the inappropriate conditions of use (contraindications). It would be dangerous to agree product safety as the basic, default position. In addition, the "test of time" criterion detects common acute adverse events, but not rare adverse events or those with a long latency. Also, today's users of herbal remedies may differ from those in earlier eras.

The governmental departments in China, such as State Administration of Traditional Chinese Medicine and State Food and Drug Administration, issue regulations and registration guidelines and procedures for CHM products. Consultation with these guidelines will help to set up regulations in the UK or other developed countries for CHM products. Consultation of the Commission E structure from Germany will also help to formulate Regulatory Guidelines for herbal products as medicines.

There is a need for regulation on the quality assurance of both practitioners and products-related treatment involving herbal products for medicinal uses. In the case of CHM products in the UK nearly all of them are imported. Some are 'manufactured' from imported dried granules by small herbal firms. They are crude herbs and ready-made products of well-used prescription products. Quality assurance and control of these have been loose and unsatisfactory. They reach the UK market probably as food or under the nutritional category. There is a lack of expertise in checking the identity of herbs. Language problem is another aspect as herbal ingredients are supplied with similarly named substitutes that could be toxic. Appropriate regulations may help to sort out problems on the quality assurance and control issues.

One way of giving guidelines for regulation is to spell out monographic control of imported herbs and herbal products. For some herbs used in the EU there are monographs issued for all of them in common use. The Commission E in Germany has produced standard monographs for controlling herbal medicines. ESCOP has commissioned the writing of standards for over 50 European herbs. With quality of herbal medicinal products assured the efficacy of them can be assessed by randomised clinical trials (RCT) before licenses can be issued. The drawback of such procedures will certainly single out 'cow-boy' practice, but also discourage manufacturers to register their products as medicines due to the high cost for getting the licences. An alternative approach should be found without compromising the issue on QSE of these products.

\section{References}

Abbot, N.C., White, A.R., Ernst, E., 1996. Complementary medicine. Nature 381, 361.

Akerele, O., 1993. Nature's medicinal bounty: don't throw it away. World Health Forum 14, 390-395.

Atherton, D.J., Sheehan, M.P., Rustin, M.H., Whittle, B., Guy, M.B., 1992. Treatment of atopic eczema with traditional Chinese medicinal plants. Pediat. Dermatol. 9 (4), 373-375.

Au, A.M., Ko, R., Boo, F.O., Hsu, R., Perez, G., Yang, Z., 2000. Screening methods for drugs and heavy metals in Chinese patent medicines. Bull. Environ. Contam. Toxicol. 65 (1), 112-119.

Barnes, J., 1997. Reports on complementary health care symposium. Pharm. J. 258, 76-77.

British Medical Association, 1993. Complementary Medicine: New Approaches to Good Practice. Oxford University Press, Oxford. 
Chan, K., Cheung, L., 2000. Chapter 7: Examples of Interactions between Chinese herbal medicines and orthodox drugs. In: Chan, K., Cheung, L. (Eds.), Interactions between Chinese Herbal Medicines and Orthodox Drugs. Harwood Academic Press, London and New York.

Chan, K., Bi, K.S., Wang, A.M., Luo, X., Yeung, H.W., 1995. Quality assessment of a popular traditional Chinese medicinal product, Liu-Shen-Wan, by fuzzy clustering analysis of HPLC pattern. In: An. Kovatsis and Helen TsoukaliPapadopoulou (Eds.), Forensic Toxicology. Aristotle University, Thessaloniki, Greece, pp. 249-252.

Chan, K., 1995. Progress in traditional Chinese medicine. Trends Pharmacol. Sci. 16, 182-187.

Chan, K., 1996. The role of complementary medicine in healthcare. Biologist 43, 50-51.

Chan, K., 1997. Regulations for registration of medicinal products from natural sources. In: Proceedings of the 6th Pacific Rim Biotechnology Conference and BioExpo'98. Hong Kong University of Science and Technology, 3 to 5 June 1998, p. 122.

Chan, K., 2002. Understanding the Toxicity of Chinese Herbal Medicinal Products. In: Chan, K., Lee, H. (Eds.), The Way Forward for Chinese Medicines. Taylor \& Francis (Chapter 4). ISBN: 0-415-27720-5.

Chaudhury, R.R., 1992. Herbal Medicine for Human Health. WHO Regional Publication SEARO No. 20.

Chuang, W.C., Wu, S.K., Sheu, S.J., Chiou, S.H., Chang, H.C., Chen, Y.P., 1995. A comparative study on commercial samples of Ginseng Radix. Planta Med. 61, 459-465.

Chuang, W.C., Wu, S.K., Sheu, S.J., Chiou, S.H., Chang, H.C., Chen, Y.P., 1996. A comparative study on commercial samples of the roots of Paeonia vitchii and P. lactiflora. Planta Med. 61, 459-465.

Covey, T.R., Lee, E.D., Henion, J.D., 1986. High-speed liquid chromatography/ tandem mass spectrometry for the determination of drugs in biological samples. Anal. Chem. 58, 2453-2460.

Eisenberg, D.M., Kessler, R.C., Foster, C., Norlock, F.E., Calkins, D.R., Debanco, T.L., 1993. Unconventional medicine in the United States. Prevalence, costs, and patterns of use. New England J. Med. 328 (4), 246-252.

Ernst, E., De Smet, 1996. Adverse effects of complementary therapies. In: Duke, M.N.G. (Ed.), Meyler's Side Effects of Drugs. Amsterdam, Elsevier.

Honda, G., Yuba, A., Kojima, T., Tabata, M., 1994. Chemotaxonomic and cytogenetic studies on Perilla frutescens var. citriodora ('Lemon Egoma'). Nat. Med. 48, 185-190.

Janetzky, K., Morreale, A.P., 1997. Probable interaction between warfarin and ginseng. Amer. J. Health-System Pharm. 54, 692-693.

Jin, Y., Berry, M.I., Chan, K., 1995. Chinese herbal medicine in the UK. Pharm. J. 255 (Suppl.), R37.

Johnson, B.A., 1997. Market Report. HerbalGram 40, 49-50.

Jones, B.D., Runikis, A.M., 1987. Interaction of ginseng with phenelzine (letter). J. Clin. Psychopharmacol. 7, 201-202.

Karunanithy, R., Sumita, K.R., 1991. Undeclared drugs in traditional Chinese anti-rheumatoid medicines. Int. J. Pharm. Practice 1, 117-119.

Koga, S., Shoyama, Y., Nishioka, I., 1991. Studies on Epimedium spp., Flavonol glycosides and isozymes. Biochem. Syst. Ecol. 19, 315-318.
Koh, H.-L., Woo, S.-O., 2000. Chinese proprietary medicine in Singapore: Regulatory control of toxic heavy metals and undeclared drugs. Drug Safety 23 (5), 351-362.

Koren, O.G., Zhuravlev, Y.N., 1998. Allozyme variations in two ginseng species Panax ginseng and $P$. quinquefolius. Advances in Ginseng Research. Proc. 7th Intl. Symp. on ginseng, Korea, September.

Lewith, G., Kenyon, J., Lewis, P., 1996. Complementary Medicine: An Integrated Approach. Oxford University Press, Oxford.

Liang, W.-L., Lin, S.-W., Yen, K.-Y., Yang, L.-L., 1998. Metal element analysis of commercial Chinese herbal medicines. Taiwan Kexue 51 (2), 37-56.

Liu, Y.M., Sheu, S.J., Chiou, S.H., Chang, S.H., Chen, Y.P., 1993. A comparative study on commercial samples of Ephedrae Herba. Planta Med. 59, 376-378.

Liu, Y.M., Sheu, S.J., Chiou, S.H., Chang, S.H., Chen, Y.P., 1994. Capillary electrophoretic analysis of alkaloids in commercial samples of Coptidis Rhizoma. Phytochem. Anal. $5,256-260$

Lo, A.C.T., Chan, K., Yeung, J.H.K., Woo, K.S., 1992. The effects of Danshen (Salvia miltiorrhiza) on pharmacokinetics and pharmacodynamics of warfarin in rats. Eur. J. Drug Metabolism Pharmacokinetics 17, 257-262.

Lo, A.C.T., Chan, K., Yeung, J.H.K., Woo, K.S., 1995. Danggui (Angelica sinesis) affects the pharmacodynamics not the pharmacokinetics of warfarin in rabbits. Eur. J. Drug Metabolism Pharmacokinetics 20, 55-60.

Magdalita, P.M., Drew, R.A., Adkins, S.W., Godwin, I.D., 1997. Morphological, molecular and cytoplasmic analyses of Carica papaya x C. cauliflora interspecific hybrids. Theor. Appl. Genet. 95, 224-229.

McRae, S., 1999. Elevated serum digoxin levels in a patient taking digoxin and Siberian ginseng. Can. Med. Assoc. J. 155, 293-295.

Sun, F., Cao, Y.Q., Liu, L.X., Xu, S.M., 1993. Isozymatic patterns for Chinese ginseng and American ginseng. Chin. Trad. Herb. Drugs 24, 148-149.

The Pharmacopoeia Commission of PRC, 2000. Pharmacopoeia of the People's Republic of China. GuangDong Science and Technology Press, GuangDong, China. English Edition. ISBN:7-5359-0945-O/R 174.

Ueng, T.-H., Kang, J.-J., Wang, H.-W., Lin, P.-C., 1997. An overview of the toxicology of commonly used traditional Chinese medicine. Yaowu Shipin Fenxi 5 (4), 241-263.

Vanhaelen, M., Vanhaelen-Fastre, R., But, P., Vanberweghem, J.L., 1994. Identification of aristolochic acid in Chinese herbs. Lancet 343,174

Wang, X.M., Xue, Y., Zhou, T.H., Sakuma, T., 1997. Characterization of traditional Chinese medicine by liquid chromatography/atmospheric pressure ionization mass spectrometry. J. Food Drug Anal. 5, 337-346.

Wong, M.K., Tan, P., Wee, Y.C., 1993. Heavy metals in some Chinese herbal plants. Biol. Trace Elem. Res. 36 (2), 135142 .

Wu, W.L., 1992. Occurrence and physiological activities of trace elements in traditional Chinese drugs. Zhonghua Yaoxue Zazhi 44 (4), 269-280.

Xu, G.-J., Chan, K., 1994. A Pictorial Compendium of Poisonous Traditional Chinese Medicinal Herbs Available in Hong Kong. Commercial Press Ltd., Hong Kong. 
Yu, H., Zhong, S., Chan, K., Berry, M.I., 1995. Pharmacognostical investigation on traditional Chinese medicinal herbs: identification of four herbs from the UK market. J. Pharm. Pharmacol. 47 (12B), 1129.
Yu, H., Zhong, S., Berry, M.I., Chan, K., 1997. Pharmacognostical investigation on traditional Chinese medicinal herbs: Identification of six herbs from the UK market. J. Pharm. Pharmacol. 49 (Suppl.), 212. 